\title{
Atributos físicos e rendimento de grãos de trigo, soja e milho em dois Latossolos compactados e escarificados
}

\author{
Crop yield and physical attributes in two oxisols compacted and chiseled
}

\author{
Deonir Secco ${ }^{\mathrm{I}}$ Dalvan José Reinert ${ }^{\mathrm{II}}$ José Miguel Reichert ${ }^{\mathrm{II}}$ \\ Vanderlei Rodrigues da Silva ${ }^{\mathrm{II}}$
}

\section{RESUMO}

A compactação do solo reduz sua qualidade estrutural em áreas manejadas sob sistema plantio direto $e$ limita o rendimento de grãos das culturas, principalmente em solos argilosos. $O$ objetivo deste trabalho foi avaliar o impacto de três estados de compactação nos atributos físicos e no rendimento de grãos de três culturas, em dois Latossolos sob plantio direto e em área escarificada. Foi determinada a densidade (Ds), a resistência do solo à penetração (Rp) e o rendimento de grãos das culturas do trigo, da soja e do milho, em Latossolo Vermelho distrófico típico-LVd, com 55\% de argila, e Latossolo Vermelho distroférrico típico-LVdf, com $61 \%$ de argila, localizados na região do planalto médio do Rio Grande do Sul. O experimento foi conduzido de 1999 a 2001. Por meio de um gride de Rp, determinado antes da implantação das culturas, foram estabelecidos três estados de compactação do solo, sendo o maior estado de compactação na região de "cabeceira" de lavoura (EC1), um estado intermediário de compactação na região compreendida entre a parte central da lavoura e a região de "cabeceira" (EC2), um estado menos compactado na parte central da lavoura (EC3) e, para caracterizar uma área isenta de compactação, foi escarificada uma parcela ao lado da lavoura. A maior Ds (1,62 e 1,54Mg $\left.\mathrm{m}^{-3}\right)$ e $\mathrm{Rp}(3,4$ e 3,8 MPa), respectivamente no LVd e LVdf, foram observadas na camada de 0,07-0,12m. Na camada de 0-0,05m, a mobilização reduziu a Ds em $26 \%$ no LVd e $15 \%$ no LVdf em relação à camada de 0,07-0,12m. O maior nível de compactação do solo (EC1) em relação ao menor nível (EC3) existente nos dois Latossolos reduziu o rendimento de grãos na cultura do trigo (18\% e $34 \%$, respectivamente, no LVd e LVdf) e milho (24\% no LVdf), mas não o rendimento da soja. A escarificação do solo aumentou o rendimento de grãos da cultura do milho e trigo em relação aos três estados de compactação do solo.
Palavras-chave: compactação do solo, plantio direto, produtividade de culturas.

\section{ABSTRACT}

Soil compaction affects structural quality in areas under no-tillage systems and reduce crop yield, particularly in clayey soils. The objective of this study was to evaluate the impact of three compaction states on crop yield and soil physical attributes in two Oxisols under no-tillage and chiseling. The soil bulk density (Ds), soil resistance to penetration ( $R p$ ) and crop yield of the wheat, soybean and corn were determined. One Oxisol (LVd) has $550 \mathrm{~g} \mathrm{~kg}^{-1}$ of clay and other (LVdf) $610 \mathrm{~g}$ $\mathrm{kg}^{-1}$ clay, located in Rio Grande do Sul plateau. The experiment was run from 1999 to 2001 in a commercial crop field mapped with respect to soil resistance to penetration. Three states of compaction were separated and mapped: a) EC1- higher compaction state located at the head of crop site; b) EC2medium state of compaction and; c) EC3 lower state of compaction toward central part of the site. To serve as no compacted area a plot was chiselled. The highest values of Ds (1.62 e $1.54 \mathrm{Mg} \mathrm{m}^{-3}$ ) and $\mathrm{Rp}(3.4$ e 3.8MPa), respectively for LVd and LVdf, cultivated under no-tillage system, were found in the layer of 0.07-0.12m. The systematic mobilization by chiseling mechanisms of the planters reduced Ds in $26 \%$ on LVd e $15 \%$ on LVdf, compaction in the layer of $0.00-0.05 \mathrm{~m}$ in relation the depth of 0.07-0.12m. The highest soil compaction state (EC1) in relation the lower state of compaction (EC3) in the two Oxisols decreased crop yield of wheat in $18 \%$ and $34 \%$, respectively for $L V d$ e $L V d$ f and corn in $24 \%$ on $L V d f$, but not of soybean. The soil chiseling increased corn and wheat grain yield in relation to the three states of soil compaction.

Key words: soil compaction, no-tillage, crop yield.

ICentro de Ciências Exatas e Tecnológicas, Universidade Estadual do Oeste do Paraná (UNIOESTE).

IIDepartamento de Solos, Universidade Federal de Santa Maria (UFSM). E-mail: dalvan@mail.ufsm.br. Santa Maria, RS, Brasil. Autor para correspondência.

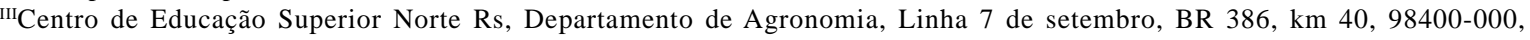
Frederico Westphalen, RS, Brasil. 


\section{INTRODUÇÃO}

As áreas cultivadas sob o sistema plantio direto vêm aumentando gradativa e sucessivamente na região Sul do Brasil. Esse sistema de manejo melhora algumas propriedades dos solos, especialmente pela redução da erosão hídrica. Entretanto ele pode compactar o solo pelo acúmulo de pressões impostas pelos pneumáticos de máquinas agrícolas, além do adensamento natural do solo (KLEIN, 1998).

Em solos de textura argilosa manejados sob sistema plantio direto, tem sido verificado maiores problemas de compactação que em solos de textura arenosa, embora MANTOVANI (1987) afirme que solos, cuja constituição seja de partículas de tamanhos similares são mais susceptíveis ao processo de compactação. Segundo o autor, isso se deve ao fato de as partículas de tamanhos diferentes se arranjarem e preencherem os poros, quando submetidas a uma pressão no solo. Entretanto, BODMAN \& CONSTANTIN (1966) já afirmavam que, em solos de textura argilosa em relação aos arenosos, há maior retenção de água por apresentarem maior volume de microporos, o que, em função do tipo, formato e tamanho dos argilominerais, pode predispor o solo a atingir um estado de compactação mais elevado.

O sistema plantio direto apresenta tendência à compactação na camada subsuperficial (0,07-0,15 m), que pode ser evidenciada pelo aumento da densidade do solo nessa camada (VIEIRA, 1981; SILVA et al., 2000a; STONE \& SILVEIRA, 2001).

Não existe um consenso entre os pesquisadores em relação a uma densidade do solo crítica, densidade a partir da qual o solo pode ser considerado como compactado. REINERT et al. (2001), com base em experimentos realizados e em alguns resultados relatados na literatura, propuseram densidade do solo de $1,45 \mathrm{Mg} \mathrm{m}^{-3}$ para caracterizar o solo como compactado em solos com mais de $550 \mathrm{~g} \mathrm{~kg}^{-1}$ de argila. Entretanto, REICHERT et al. (2003, 2007), com base em trabalhos que avaliaram o intervalo hídrico ótimo (IHO), relatam que as densidades do solo consideradas críticas em função da classe textural do solo e quando o IHO é zero variam de 1,25 a 1,30 e de 1,30 a $1,40 \mathrm{Mg} \mathrm{m}^{-3}$, respectivamente, para solos de textura muito argilosa e argila.

A resistência do solo à penetração aumenta exponencialmente com o aumento da densidade e decresce com o aumento do conteúdo de água (CASSEL \& LAL, 1992). MENDES (1989), em Latossolo muito argiloso, observou que, quando a resistência do solo à penetração foi superior a 1,8MPa, ocorreu decréscimo em $70 \%$ no enraizamento da cultura do milho. Alguns autores sugerem Rp de 2,0MPa como sendo limitante ao crescimento radicular para a maioria das espécies cultivadas (TAYLOR et al., 1966), mas cada espécie exerce pressão de crescimento radicular diferenciada (CAMARGO \& ALLEONI,1997). Assim, para solos de textura argilosa, quando estes apresentarem resistência do solo à penetração superior a 2,0MPa, densidade maior que $1,30 \mathrm{Mg} \mathrm{m}^{-3}$ para classe textural muito argiloso e $1,40 \mathrm{Mg} \mathrm{m}^{-3}$ para classe textural argila e volume de macroporos inferior a 10 \%, há evidências de que estão compactados (REICHERT et al., 2003, 2008). Entretanto, em virtude da resistência à penetração estar diretamente relacionada à umidade do solo, tem sido difícil estabelecer, no campo, a resistência do solo à penetração crítica. Com o aumento da umidade, a resistência do solo à penetração pode mudar rapidamente de uma possível condição limitante para outra não-limitante.

Em vista disso e em função de outras variáveis afetarem o crescimento e desenvolvimento das culturas como disponibilidade de água e nutrientes, ataque de pragas e doenças e presença de invasoras, torna-se difícil avaliar o impacto de estados de compactação do solo no rendimento de grãos, em condições de lavoura. ADAMS \& WULFSOHN (1997), em solo franco siltoso e franco argiloso, encontraram reduções de $13 \%$ na produtividade de grãos de trigo e 7,5\% na do milho, quando a densidade do solo passou em média de 1,07 para 1,19Mg m³. . McAFEE et al. (1989) encontraram redução do rendimento de grãos de 30 \% na cultura da aveia em um solo de textura argilosa, quando a resistência do solo à penetração variou de 3,5 a 4,5MPa. SECCO et al. (2004), estudando o rendimento de grãos de seis cultivares de soja em um Latossolo Vermelho sob plantio direto e quatro estados de compactação do solo, sendo três gerados artificialmente por meio da passagem de um rolo compactador, constataram que o rendimento de grãos das cultivares de soja não foi influenciado pela compactação do solo.

O objetivo deste trabalho foi avaliar o efeito de três estados de compactação na densidade e na resistência do solo à penetração e no rendimento de grãos de trigo, soja e milho, em dois Latossolos sob plantio direto e em área escarificada.

\section{MATERIAL E MÉTODOS}

O experimento foi instalado no município de Cruz Alta, em Latossolo Vermelho distrófico típico argiloso (555g kg-1 de argila)-LVd, e no município de Coronel Barros, em Latossolo Vermelho distroférrico 
típico argiloso (610 $\mathrm{g} \mathrm{kg}^{-1}$ de argila)-LVdf (EMBRAPA, 1999), no Rio grande do Sul (RS), de 1999 a 2001. Para o LVd, a área vinha sendo cultivada há 14 anos em sistema plantio direto, com rotação de culturas no inverno (trigo, aveia e nabo forrageiro) e verão (milho e soja). No LVdf, a área já vinha sendo cultivada há sete anos em sistema plantio direto com o cultivo sucessivo de trigo no inverno e soja no verão. A região do Rio Grande do Sul que compreende os municípios de Cruz Alta e Coronel Barros apresenta clima classificado como Cfalg2, segundo o sistema Köppen, isto é, subtropical úmido, sem estiagem típica. A temperatura média do mês mais quente é superior a $22^{\circ} \mathrm{C}$ e do mês mais frio é superior a $3^{\circ} \mathrm{C}$ e inferior a $18^{\circ} \mathrm{C}$. A precipitação média anual é maior do que $1600 \mathrm{~mm}$, com tendência de maiores precipitações na primavera e no verão.

A área do estudo de cada solo foi de 50x30m, onde foi determinada a resistência do solo à penetração (Rp), no mesmo dia, numa malha de 4 x 2m. Nos dois solos, os estados de compactação foram mapeados tomando como base isolinhas de Rp na camada de 0,07 a $0,12 m$, por ser a camada mais compactada. O critério diferencial das classes de Rp foi baseado na distribuição da Rp, criando-se três classes ou estados de compactação (baixo, médio e alto) em diferentes posições (cabeceira, intermediária e central da área), sendo respectivamente denominadas de EC1, EC2 e EC3. Nas três condições, foram coletados anéis volumétricos para medir a densidade do solo, seguindo metodologia descrita em EMBRAPA(1997) (Tabela 1).

A Rp foi determinada até a profundidade de 0,40 m, com o uso de um penetrógrafo SOILCONTROL ${ }^{\mathrm{R}}$

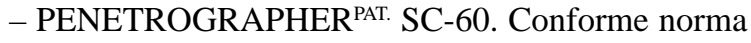
ASAE R313, a Rp foi obtida a uma velocidade uniforme de penetração de $1890 \mathrm{~mm}$ por minuto, utilizando-se um cone de diâmetro de base de 12,8mm. A Rp foi expressa em MPa. Cada Rp de cada ponto amostral da malha, para gerar o mapa de resistência, representa uma média de 10 repetições.

A densidade (Ds) e a umidade do solo foram determinadas com cilindros de $0,03 \mathrm{~m}$ de altura e $0,05 \mathrm{~m}$ de diâmetro nas camadas de: 0,00-0,05, 0,05-0,10, 0,100,15, 0,15-0,20, 0,20-0,30 e de 0,30-0,40m (EMBRAPA, 1997), para detectar a camada de solo com maior estado de compactação e determinar a profundidade máxima de influência do tráfego de máquinas. Em cada camada e estado de compactação, foram feitas duas repetições, num total de 12 pontos aleatórios por tratamento.

Tabela 1 - Caracterização dos estados de compactação pela resistência à penetração (Rp) e densidade do solo (Ds) na camada de 0,07 a 0,12m, na amostragem para definição dos tratamentos, e valores médios de Ds nos três estados de compactação, nas camadas de 0,0-0,05, 0,07-0,12 e 0,20-0,25 m, no Latossolo Vermelho distrófico (Lvd) e Latossolo Vermelho distroférrico (LVdf).

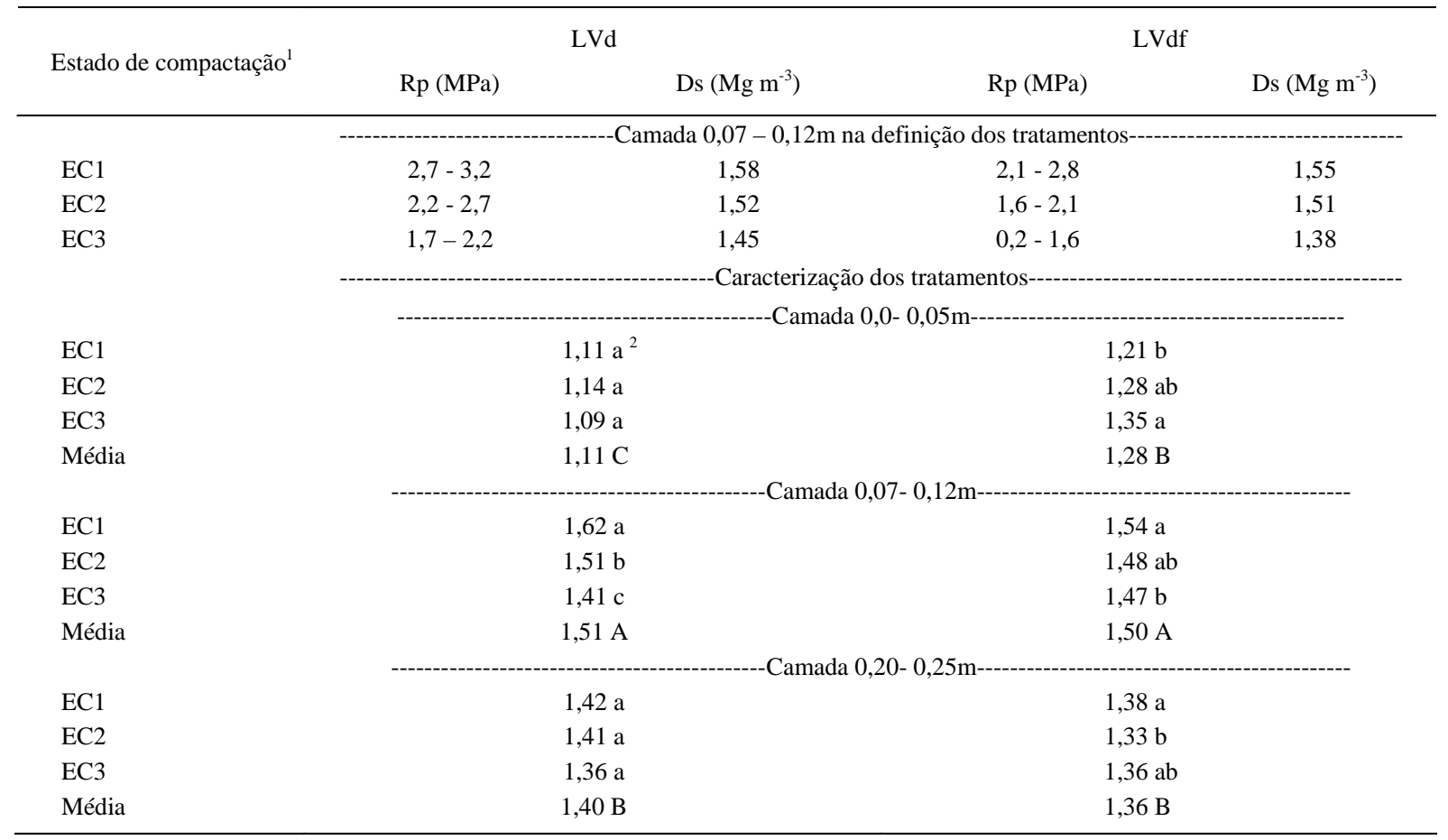

${ }^{1}$ EC1: estado de compactação maior, EC2: estado de compactação intermediário e EC3: estado de compactação menor.

${ }^{2}$ Médias de tratamento seguidas de mesma letra minúscula na coluna não diferem significativamente pelo teste $t$ de Student $(\mathrm{P}<0,05)$. Médias para cada camada seguidas por letras maiúsculas na coluna comparam camadas distintas.

Ciência Rural, v.39, n.1, jan-fev, 2009. 
Tendo em vista que a maior Rp ocorreu na camada de 0,07-0,12m, foram estabelecidas as três camadas de monitoramento, sendo uma logo acima desta $(0,00$ $0,05 \mathrm{~m})$ e outra mais abaixo $(0,20-0,25 \mathrm{~m})$.

A adubação e o manejo das culturas foram realizados de acordo com a recomendação técnica para a região. Na implantação das culturas da soja e do milho nos dois Latossolos, a semeadora-adubadora estava equipada com mecanismo de sulcamento para deposição do adubo do tipo facão, o qual mobilizava o solo, na linha da semeadura, até a profundidade de 0,10m aproximadamente. A opção de utilização do mecanismo de sulcamento tipo facão na semeadoraadubadora ocorreu devido à disponibilidade existente. Além disso, houve um cuidado para evitar que a área de estudo não sofresse tratamento diferenciado em relação às lavouras da região. Assim, procurou-se não alterar as reais condições de manejo das lavouras para isolar o efeito dos estados de compactação do solo.

Na safra 2000/2001, uma área paralela à área experimental foi escarificada até aproximadamente $0,2 \mathrm{~m}$ de profundidade, a qual foi assumida como livre de compactação. Isso foi confirmado após análise realizada em trincheira ao longo de toda a faixa de ação do implemento. Tendo em vista dificuldades na determinação da Rp e Ds após a escarificação dos mesmos, não foram medidos esses atributos na condição imediatamente após a mobilização.

O rendimento de grãos das culturas foi determinado em áreas de 6; 9 e $16 \mathrm{~m}^{2}$, respectivamente, para o trigo, a soja e o milho, em cinco subamostras orientadas pelos mapas de resistência e expresso em $\mathrm{Mg} \mathrm{ha}^{-1}$, com umidade corrigida para $13 \%$.

A análise estatística foi realizada considerando-se um delineamento inteiramente casualizado e constou de comparações entre médias de variáveis de solo e das culturas nos três estados de compactação e na área escarificada, por meio do teste t de Student ao nível de 5\% de significância.

\section{RESULTADOS E DISCUSSÃO}

No LVd ocorreu diferença significativa na Ds entre os três estados de compactação (EC) apenas na camada de $0,07-0,12 \mathrm{~m}$. O estado de compactação EC1 apresentou Ds superior ao EC2 e EC3. Isso pode ser explicado pelo acúmulo das tensões impostas pelo tráfego de máquinas agrícolas na superfície do solo. Na camada de 0,0-0,05m, a mobilização sistemática do solo pelos mecanismos sulcadores das semeadorasadubadoras, aliada ao maior conteúdo de matéria orgânica nessa camada, reduziram a compactação (Tabela 1).
No LVdf, a maior Ds foi encontrada na camada de 0,07-0,12m. O EC1 apresentou Ds semelhante ao EC2 e superior ao EC3, em virtude das mesmas razões comentadas para o LVd (Tabela 1 ). Na camada de 0,0-0,05m, o EC3 apresentou Ds superior ao EC1, enquanto na camada de 0,20-0,25m o EC1 apresentou Ds superior ao EC2 e semelhante ao EC3. Isso demonstra que, a exemplo do LVd, ocorreu incremento da Ds na camada de 0,07-0,12m. Essas maiores Ds encontradas nos dois Latossolos, na camada de 0,07-0,12m, concordam com os resultados encontrados por VIEIRA (1981), SILVA et al. (2000a), REICHERT (2008), indicando que, no sistema plantio direto, há tendência à compactação na camada subsuperficial, porém em profundidade menor do que para preparos que mobilizam o solo (KLEIN, 1998). Na camada de 0,07-0,12m, a Ds para esses solos ultrapassam 1,25 a $1,40 \mathrm{Mg} \mathrm{m}^{-3}$, consideradas como limite para considerar um solo de textura argilosa a muito argilosa como sendo compactado (REICHERT et al., 2003).

A Rp no LVd diferiu entre os estados de compactação e em relação à área que havia sido escarificada. A maior Rp foi encontrada na camada de 0,07-0,12m, nos três estados de compactação (Figuras 1a e 1b). Nas duas condições de umidade do solo, o estado de compactação EC1 apresentou Rp superior na camada de 0,07-0,12m, em relação ao EC3 e à área escarificada. Nessas condições de umidade do solo, o EC1 apresentou maior Rp e a área escarificada a menor Rp, principalmente na camada de 0,07-0,12m. Nesse solo, não se observou diferença significativa na Rp entre os estados de compactação a partir de $0,30 \mathrm{~m}$ de profundidade.

No LVdf, a Rp diferiu entre os estados de compactação e em relação à área que havia sido escarificada. A maior Rp ocorreu na camada de 0,070,12m, nos três estados de compactação e na área escarificada (Figuras 1c e 1d ).

Em ambos os Latossolos estudados, houve uma relação de dependência da Rp em relação à Ds, principalmente na camada com maior Ds $(0,07-0,12 \mathrm{~m})$, em função do acúmulo de tensões impostas. Além disso, houve relação inversa entre a Rp e a umidade do solo. As relações da Rp com a Ds e com o teor de água no solo estão de acordo com GENRO JR. et al. (2004). Nos dois Latossolos, na camada de 0,07-0,12m, mesmo quando o teor de água estava próximo da capacidade de campo (Figuras 1a e 1c), a Rp no EC1 foi superior a 2,0MPa, valor esse sugerido como limitante para algumas culturas. Além disso, ao se comparar a Rp entre os Latossolos, foi verificado que o LVdf (mais argiloso) apresentou maior Rp.

Ciência Rural, v.39, n.1, jan-fev, 2009. 


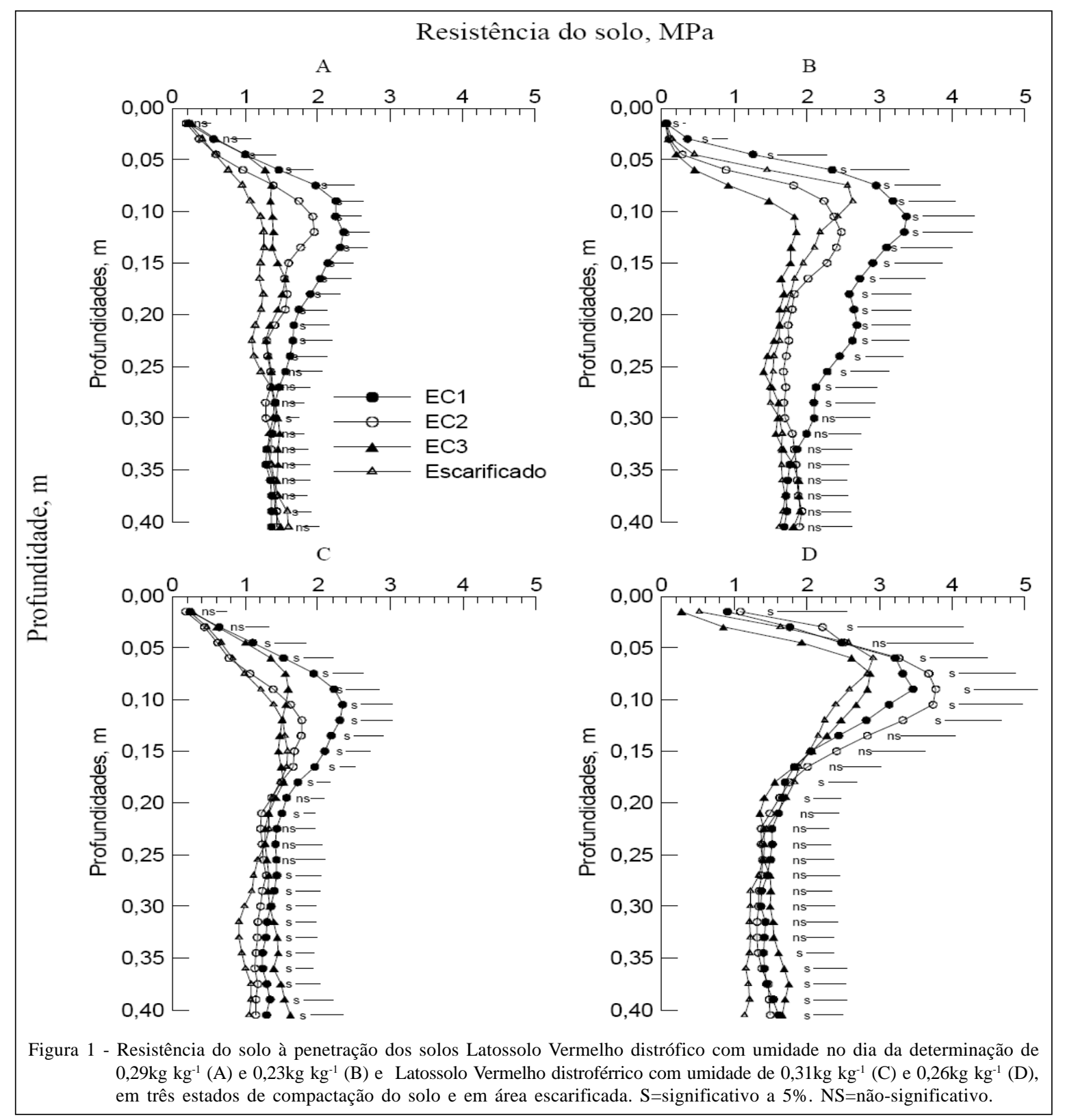

O rendimento de grãos da cultura do trigo para o LVd, safra 1999, foi inferior no maior estado de compactação (EC1) em relação aos estados de compactação EC2 e EC3 (Tabela 2). Nesse solo e estado de compactação, os valores médios de Ds e Rp, na camada de 0,07 a $0,12 \mathrm{~m}$, foram, respectivamente, de $1,62 \mathrm{Mg} \mathrm{m}^{-3}$ e 2,65 MPa. A diferença de rendimento de grãos representou 18,35 \% de inferioridade no EC1 em relação ao EC3, que apresentou valores médios de Ds e Rp, respectivamente, de $1,41 \mathrm{Mg} \mathrm{m}^{-3}$ e $1,77 \mathrm{MPa}$.

No LVdf, safra 2000, o maior estado de compactação (EC1) também proporcionou menor rendimento de grãos. Isso diferiu dos demais estados de compactação, em que essa diferença representou um decréscimo de rendimento de 34,05\% em relação ao menor estado de compactação (EC3) (Tabela 2). Nesse solo, na camada de 0,07 a $0,12 \mathrm{~m}$, a Ds e a Rp média no EC1 foi, respectivamente, de $1,54 \mathrm{Mg} \mathrm{m}^{-3}$ e 3,26MPa, enquanto que no EC3 foram, respectivamente, de $1,47 \mathrm{Mg} \mathrm{m}^{-3}$ e 2,95MPa. Esses resultados concordam com McAFEE et al. (1989), os quais encontraram redução do rendimento de grãos de $30 \%$ na cultura da aveia em solo de textura argilosa com Rp variando entre 3,5 e 4,5MPa.

O rendimento de grãos de soja não diferiu entre os estados de compactação e/ou parcela

Ciência Rural, v.39, n.1, jan-fev, 2009. 
Tabela 2 - Rendimento de grãos e rendimento relativo da cultura do trigo e do milho no Latossolo Vermelho distrófico ( LVd-safra 1999) e no Latossolo Vermelho distroférrico ( LVdf-safra 2000). Rendimento de grãos da cultura da soja nas safras de 1999/00, 2000/01, em três estados de compactação do solo e na área escarificada.

\begin{tabular}{|c|c|c|c|c|c|c|}
\hline \multirow{2}{*}{ Estados de compactação } & \multicolumn{3}{|c|}{ LVd } & \multicolumn{3}{|c|}{ LVdf } \\
\hline & \multicolumn{2}{|c|}{ Rendimento de grãos $\left(\mathrm{Mg} \mathrm{ha}^{-1}\right)$} & \multicolumn{2}{|c|}{ Rendimento relativo ( \% ) $\begin{array}{c}\text { Rendimento de grãos } \\
\mathrm{ha}^{-1} \text { ) }\end{array}$} & (Mg & $\begin{array}{l}\text { Rendimento relativo } \\
\qquad(\%)\end{array}$ \\
\hline & --------- & ----------- & 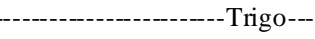 & - & --- & - \\
\hline EC1 & & $1,87 b^{1}$ & 82 & $1,24 \mathrm{~b}$ & & 66 \\
\hline EC2 & & 2,15 a & 94 & 1,65 a & & 88 \\
\hline EC3 & & 2,29 a & 100 & 1,88 a & & 100 \\
\hline Escarificada & & $\mathrm{Nd}^{2}$ & & $\mathrm{Nd}^{2}$ & & \\
\hline EC1 & & $8,11 \mathrm{ab}^{1}$ & 91 & $4,46 \mathrm{c}$ & & 62 \\
\hline EC2 & & 7,43 b & 83 & $6,16 \mathrm{~b}$ & & 85 \\
\hline EC3 & & $8,11 \mathrm{ab}$ & 91 & $6,22 \mathrm{~b}$ & & 86 \\
\hline \multirow[t]{2}{*}{ Escarificada } & & 8,92 a & 100 & 7,24 a & & 100 \\
\hline & $1999 / 2000$ & $2000 / 2001$ & & $2000 / 2001$ & & \\
\hline EC1 & $1,77 a^{1}$ & $3,80 \mathrm{a}$ & & 2,69 a & & 85 \\
\hline EC2 & 1,72 a & 3,53 a & & 2,70 a & & 86 \\
\hline EC3 & 1,82 a & 3,23 a & & 3,16 a & & 100 \\
\hline Escarificada & $\mathrm{Nd}^{2}$ & 3,54 a & & 3,15 a & & 100 \\
\hline
\end{tabular}

${ }^{1}$ Médias de tratamentos seguidas por letras distintas na coluna diferem significativamente pelo teste $\mathrm{t}$ de Student $(\mathrm{P}<0,05)$.

${ }^{2}$ Não determinada, pois a escarificação ocorreu a partir da safra 2000/2001.

escarificada nos dois Latossolos (Tabela 2). Esses resultados sugerem duas possíveis explicações. A primeira é que os estados de compactação do solo não foram suficientemente elevados para promoverem decréscimos na produção da soja. Essa possível explicação está baseada no fato de que SILVA et al. (2000b), ao compararem os estados EC1 e EC3 nos mesmos solos e locais, não encontraram diferença significativa na densidade de comprimento radicular da soja (cm de raiz $\mathrm{cm}^{-3}$ de solo) no LVd, aos 90 dias após a semeadura na safra 1999/2000. Esses autores sugerem que o maior estado de compactação ocorrente na área (EC1) não foi limitante para restringir o crescimento radicular da soja. Nesse caso, as médias de Ds de 1,62 e 1,54Mg m ${ }^{-3}$ e de Rp de 2,65 e 3,26MPa no EC1, respectivamente, no LVd e LVdf, não foram restritivos para a soja em condições de lavoura. Esses resultados concordam com SECCO et al. (2004), os quais ao estudarem o rendimento de grãos de seis cultivares de soja em um Latossolo Vermelho distrófico sob plantio direto e quatro estados de compactação do solo, constataram que o rendimento de grãos não foi afetado significativamente com o aumento da compactação do solo. Os autores concluíram que os estados de compactação não foram suficientemente elevados para provocar redução de rendimentos de grãos nas seis cultivares avaliadas.

Outra possível explicação para a soja não ter apresentado diferença significativa no rendimento de grãos entre os estados de compactação do solo é o efeito positivo da mobilização do solo pelos mecanismos sulcadores da semeadora-adubadora, os quais mobilizaram o solo até aproximadamente $0,1 \mathrm{~m}$ de profundidade.

O rendimento de grãos do milho não diferiu significativamente entre os estados de compactação no LVd, na safra 2000/2001. Contudo, houve diferença significativa apenas entre a área escarificada e o EC2, com rendimento de grãos 17\% menor no EC2 (Tabela 2). No LVdf, na safra 2000/2001, a parcela escarificada apresentou maior rendimento de grãos de milho, cuja diferença foi significativa em relação aos demais estados de compactação do solo. A produção de milho da área escarificada, em relação aos estados de compactação EC1, EC2 e EC3, foi superior, respectivamente, em 38; 15 e 14\%. Entre os estados de compactação também houve diferença significativa entre o rendimento de grãos, onde o EC1 teve produção relativa $24 \%$ inferior em relação ao EC3. Isso demonstra que, para o LVdf, os valores médios de Ds de 1,54Mg m 
e de Rp de 3,26MPa foram suficientemente elevados para reduzir o rendimento de grãos da cultura do milho. A cultura do milho, a exemplo da cultura do trigo, foi sensível aos estados de compactação existentes nos dois Latossolos, com mais intensidade no LVdf. Isso evidencia que as gramíneas, em comparação com as leguminosas, foram mais suscetíveis aos efeitos negativos nos atributos físicos do solo impostos pelos estados de compactação. Esses resultados encontrados nos dois Latossolos concordam parcialmente com os resultados encontrados por ADAMS \& WULFSOHN (1997) para um solo franco siltoso e franco argiloso. Nesse estudo houve redução no rendimento de grãos de $13 \%$ para o trigo e $7,5 \%$ para o milho, quando a Ds do solo passou de 1,07 para $1,19 \mathrm{Mg} \mathrm{m}^{-3}$.

\section{CONCLUSÕES}

As maiores Ds e Rp, em Latossolos cultivados sob sistema plantio direto, ocorrem na camada de 0,07-0,12m. Os níveis de compactação do solo existentes nos dois Latossolos reduziram o rendimento de grãos na cultura do milho e trigo, mas não o rendimento da soja, indicando que valores de Ds e Rp observados são restritivos ao crescimento e desenvolvimento dessas culturas. A escarificação do solo aumentou o rendimento de grãos da cultura do milho no LVdf em relação aos três estados de compactação do solo, porém não modificou o rendimento da soja.

\section{AGRADECIMENTOS}

Os autores agradecem o financiamento da Fundação de Amparo à Pesquisa do Estado do Rio Grande do Sul (Fapergs) e do Conselho Nacional de Desenvolvimento Científico e Tecnológico (CNPq), para a realização deste trabalho.

\section{REFERÊNCIAS}

ADAMS, B.A.; WULFSOHN, D. Variation of the critical-state boundaries of an agricultural soil. Eur J Soil Sci, v.48, p.739748, 1997.

BODMAN, G.B.; CONSTANTIN, G.K. Influence of particle sizes distribution in soil compaction. Hilgaria, v.36, p.56791, 1966.

CAMARGO, O.A. de; ALLEONI, L.R.F. Compactação do solo e o desenvolvimento das plantas. Piracicaba, 1997. 132p.

EMPRESA BRASILEIRA DE PESQUISA AGROPECUÁRIA. Centro Nacional de Pesquisa de Solos. Manual de métodos de análise de solo. 2.ed. rev. atual. Rio de Janeiro: EMBRAPA, 1997. 212p.

EMPRESA BRASILEIRA DE PESQUISA AGROPECUÁRIA. Centro Nacional de Pesquisa de Solos. Ministério da Agricultura e do Abastecimento. Sistema brasileiro de classificação de solos. Brasília, 1999. 412p.

GENRO JUNIOR, S.A. et al. Variabilidade temporal da resistência à penetração de um latossolo argiloso sob semeadura direta com rotaçãode culturas. R Bras Ci Solo, v.28, p.477484, 2004.

KLEIN, V.A. Propriedades físico-hídrico-mecânicas de um Latossolo roxo, sob diferentes sistemas de uso e manejo. 1998. Tese (Doutorado) - Escola Superior de Agricultura "Luiz de Queiroz", Piracicaba, SP.

MANTOVANI, E.C. Compactação do solo. Informação Agropecuária, v.13, 147p, 1987.

McAFFEE, M. et al. Effects of pre-sowing compaction on soil physical properties, soil atmosphere and growth of oats on a clay soil. J Soil Sci, v.40, p.707-717, 1989.

MENDES, R.C.A. Restrições físicas ao crescimento radicular num Latossolo muito argiloso. 1989. $81 \mathrm{f}$. Dissertação (Mestrado) - Universidade Nacional de Brasília, Brasília, DF.

REICHERT, J.M. et al. Qualidade dos solos e sustentabilidade de sistemas agrícolas. Ciência \& Ambiente, v.27, p.29-48, 2003.

REICHERT, J.M. et al. Compactação do solo em sistemas agropecuários e florestais: identificação, efeitos, limites críticos e mitigação. Tópicos Ci Solo, v.5, p.49-134, 2007.

REICHERT, J.M. et al. Reference bulk density and critical degree-of-compactness for no-till crop production in subtropical highly weathered soils. Soil Till Research, v.online, p.1-13, 2008.

REINERT, D.J. et al. Propriedades físicas de solos em sistema plantio direto irrigado. CARLESSO, R. et al. (Eds.). Irrigação por aspersão no Rio Grande do Sul. Santa Maria: Palloti, 2001. p.114-133.

SECCO, D. et al. Produtividade de soja e propriedades físicas de um Latossolo submetido a sistemas de manejo e compactação. R Bras Ci Solo, v.28, p.797-804, 2004.

SILVA, V.R. et al. Densidade do solo, atributos químicos e sistema radicular do milho afetados pelo pastejo e manejo do solo. R Bras Ci Solo, v.24, p.191-199, 2000a.

SILVA, V.R. et al. Estado de compactação e sistema radicular de soja (Glycine Max (L.) Merrill). In: REUNIÃO BRASILEIRA DE MANEJO E CONSERVAÇÃO DO SOLO E DA ÁGUA, 13., Ilhéus-BA, 2000. Anais... Ilhéus: CEPLAC, 2000b. CD Rom.

STONE, L.R.; SILVEIRA, P.M. Efeitos do sistema de preparo e da rotação de culturas na porosidade e densidade do solo. $\mathbf{R}$ Bras Ci Solo, v.25, p.395-401, 2001.

TAYLOR, H.M. et al. Soil strength-root penetration relations for medium- to coarse-textured soil materials. Soil Sci, v.102, p.18-22, 1966.

VIEIRA, M.J. Propriedades físicas do solo. In: FUNDAÇÃO INSTITUTO AGRONÔMICO DO PARANÁ. Plantio direto no estado do Paraná. Londrina, 1981. p.19-30. (IAPAR Circular, 23). 